\title{
Opioids should not be prescribed for chronic pain after spinal cord injury
}

\author{
Thomas N. Bryce ${ }^{1}$
}

Received: 28 March 2018 / Revised: 11 May 2018 / Accepted: 13 May 2018

(c) International Spinal Cord Society 2018

\begin{abstract}
Most people with spinal cord injury (SCI) have chronic pain and effective treatments have not been identified. Within the first two decades of the 21 st century, opioids have been commonly prescribed in an attempt to manage pain after SCI, however, the risks and absence of benefit of opioids have become more apparent as opioid crises have developed around the world. This perspective is an argument for why opioids should no longer be prescribed to treat chronic pain after SCI.
\end{abstract}

Chronic pain after spinal cord injury (SCI) is common with nearly four out of five people reporting ongoing pain of which approximately half is musculoskeletal and half is neuropathic [1, 2]. Treatment efficacy is often suboptimal as evidenced by the persistently high prevalence of pain over time $[1,2]$. As a result it is not surprising that persons with SCI are both significantly more likely to be long-term users of short-acting opioids and to be more likely to be taking high doses of long-acting opioids than their propensity score-matched controls [3]. It is also likely that clinicians who treat people with SCI will encounter someone whose pain is not controlled despite being treated with all the recommended treatments supported by the best available evidence [4]. It is at this point that the treating clinician faced with a patient with seemingly uncontrolled pain and few options needs to make a decision as to whether opioids should be started if the individual is not being treated with them already or dose escalated, continued, or tapered if the individual is currently being treated with opioids.

There are at least four reasons why a clinician should not be tempted to begin or escalate opioids for the treatment of SCI related pain, either for musculoskeletal pain or for neuropathic SCI pain. Moreover, if a person is already being prescribed opioids, the clinician should slowly begin to taper the opioids off. These reasons include (1) a lack of

Thomas N. Bryce

Thomas.bryce@mountsinai.org

1 Department of Rehabilitation Medicine, Icahn School of Medicine at Mount Sinai, 1 Gustave L. Levy Pl, New York, NY 10029, USA evidence for the effectiveness of chronic opioids for decreasing pain intensity or improving quality of life; (2) the avoidance of a risk of opioid overdose causing respiratory depression and death; (3) the avoidance of adverse effects of opioids such as constipation, mental slowness, and hormonal depression; and (4) the avoidance of the risk of developing an opioid use disorder.

\section{Lack of effectiveness}

There are no randomized controlled (Level 1) studies that support the premise that opioids are effective for the treatment of pain after SCI in either the short or long term, except for one small study supporting the effectiveness of tramadol in the short term [4-7]. This lack of evidence for effectiveness in the long term is not unique to pain after SCI, as summarized in the recent United States Centers for Disease Control and Prevention Guideline for prescribing opioids for chronic pain [8].

Moreover, findings from a recent systematic review of chronic opioid dose reduction interventions suggest that individuals who taper off opioids, not uncommonly, report improvements in function without an associated worsening in pain, actual decreased pain levels, and improvements in quality of life [9]. Potential reasons for these perhaps nonintuitive outcomes related to long term opioid dose reduction or discontinuation include (1) alleviation of common opioid adverse effects that can worsen function and quality of life, such as constipation, fatigue, poor sleep, and depressed mood; (2) resolution of opioid-induced hyperalgesia; and (3) initiation of non-opioid pain management 
interventions [9]. There is also some evidence that the reluctance of many individuals on chronic opioid therapy to begin to decrease their intake of opioids may actually be related to a fear of opioid withdrawal rather than any actual benefit from the drug [10].

\section{Risk of overdose}

Opioids frequently cause physical dependence and users develop tolerance, which often leads to a gradual dose escalation of opioids as there is a perceived loss of effectiveness over time [11]. Dose escalation is a significant concern as it increases an individual's risk for fatal overdose. The odds of overdose increase as the dose per day increases. Comparisons of opioid doses administered per day between different drugs can be made simply by converting each to a common measure of morphine milligram equivalent (MME) doses per day by multiplying the daily dose of any opioid by a conversion factor (see Table 1). Persons taking between 20 and 50 MME per day of opioids have twice the odds of overdosing compared to those who take less [8]. For those taking doses between 50 and 100 MME per day the odds of overdosing increases to nearly five times while for doses of more than $100 \mathrm{MME} /$ day the odds approach ten times the odds that are associated with taking less than $20 \mathrm{MME} /$ day [8].

Another way of demonstrating the magnitude of overdose risk is illustrated by a recent study of persons with non-SCI non-cancer pain, where one in 32 individuals prescribed more than $200 \mathrm{MME}$ per day died from an opioid related overdose [12]. Persons with cervical and

Table 1 Morphine milligram equivalent (MME) doses for commonly prescribed opioids [21]

\begin{tabular}{ll}
\hline Opioid & Conversion factor \\
\hline Codeine & 0.15 \\
Fentanyl transdermal (in mcg/h) & 2.4 \\
Hydrocodone & 1 \\
Hydromorphone & 4 \\
Methadone & 3 \\
Morphine & 1 \\
Oxycodone & 1.5 \\
Oxymorphone & 3 \\
Tramadol & 0.1 \\
\hline
\end{tabular}

${ }^{a}$ Multiply the dose for each opioid by the conversion factor to determine the dose in MMEs. For example, tablets containing hydrocodone $5 \mathrm{mg}$ and acetaminophen $300 \mathrm{mg}$ taken four times a day would contain a total of $20 \mathrm{mg}$ of hydrocodone daily, equivalent to 20 MME daily; extended-release tablets containing oxycodone $10 \mathrm{mg}$ and taken twice a day would contain a total of $20 \mathrm{mg}$ of oxycodone daily, equivalent to $30 \mathrm{MME}$ daily. All doses are in $\mathrm{mg} /$ day except for fentanyl, which is $\mathrm{mcg} / \mathrm{h}$ upper thoracic SCI have additional further risks for overdose. These include respiratory insufficiency related to the SCI, sleep disordered breathing, and polypharmacy with other respiratory depressant medications. The prevalence of sleep disordered breathing in persons with complete tetraplegia is over $50 \%$ [13] while $70 \%$ to $85 \%$ of persons taking opioids have sleep disordered breathing, of which a high proportion is moderate to severe [14]; the combination of etiologies of sleep disordered breathing likely increases the severity of the effect.

With regards to polypharmacy, one particularly dangerous combination of drug classes is that of opioids and benzodiazepines. Depending on the series cited, one to two thirds of fatal overdoses involve a combination of opioids and benzodiazepines [15, 16]; the latter not uncommonly prescribed for recalcitrant spasticity, anxiety, and sometimes insomnia in persons with SCI. Concurrent use of a benzodiazepine and an opioid increases the risk of overdose four to tenfold over opioid use alone $[17,18]$. Of note, the discontinuation of opioids and benzodiazepines done separately have been shown to decrease the severity of sleep disordered breathing $[14,19]$.

\section{Other adverse effects}

Opioids have other adverse effects other than the respiratory depression. Opioids decrease gastrointestinal mobility, which can lead to poor bowel emptying, abdominal distension, bloating, and secondary chronic abdominal pain. Additionally, opioids significantly affect levels of endogenous hormones including luteinizing hormone, folliclestimulating hormone, estrogen, and testosterone, which can adversely affect libido and fertility [11]. Opioids also commonly cause sedation and impaired cognition. In the previously referenced tramadol study, nearly half of subjects discontinued participation in the trial due to adverse effects [6].

\section{Risk of opioid use disorder}

Opioid use disorder (previously classified as opioid abuse) is defined in the Diagnostic and Statistical Manual of Mental Disorders, 5th edition (DSM-5) as a problematic pattern of opioid use leading to clinically significant impairment or distress, manifested by at least two defined criteria occurring within a year [20]. The prevalence of this condition cited in the literature among patients with chronic pain on opioid therapy ranges between 3 and $26 \%$ in primary care settings and between 2 and $14 \%$ in a pain clinic settings [8]. The odds of developing an opioid use disorder has been found to correlate with the daily dose of opioid 
prescribed. When compared to a person not being prescribed opioids, the odds of developing an opioid use disorder increase from 15 times for a person taking less than 36 MME per day to 30 times for a person taking between 36 and $120 \mathrm{MME}$ per day. The odds of developing an opioid use disorder further increases to 122 times for a person taking more than $120 \mathrm{MME}$ per day [21]. This correlates with a risk of developing an opioid use disorder of $1 \%$ with lower-dose (less than $36 \mathrm{MME}$ ) and 6\% with higher-dose (more than $120 \mathrm{MME}$ ) chronic opioid therapy [21].

It should be noted that there are effective treatments for opioid use disorder, specifically medication-assisted treatment with buprenorphine, naltrexone, or methadone maintenance therapy in combination with behavioral therapies [8], however the current societal need outpaces the supply, at least in the United States [22].

Finally, although there are likely some individuals with SCI who have chronic pain, either neuropathic or nociceptive, that may respond to opioids and experience an improved quality of life, and not require escalating doses, this may not be the usual case. Prescribers in the United States seem to be starting to get this message and opioid prescribing, which peaked in 2010 with nearly 250 billion MME, was down to nearly 200 billion MME in 2016, a decrease of $20 \%$, although still much higher than the 50 billion MME prescribed in 1992 [23]. It is interesting to note that the decrease could nearly all be accounted for by a decrease in prescription of extended release opioids.

\section{References}

1. Cardenas DD, Bryce TN, Shem K, Richards JS, Elhefni H. Gender and minority differences in the pain experience of people with spinal cord injury. Arch Phys Med Rehabil. 2004;85:1774-81.

2. Finnerup NB, Jensen MP, Norrbrink C, Trok K, Johannesen IL, Jensen TS, et al. A prospective study of pain and psychological functioning following traumatic spinal cord injury. Spinal Cord. 2016;54:816-21.

3. Hand BN, Krause JS, Simpson KN, Dose and duration of opioid use in propensity score-matched, privately insured opioid users with and without spinal cord injury. Arch Phys Med Rehabil. 2018;99:855-61.

4. Guy SD, Mehta S, Casalino A, Côté I, Kras-Dupuis A, Moulin DE, et al. The CanPain SCI Clinical Practice Guidelines for Rehabilitation Management of Neuropathic Pain after Spinal Cord: recommendations for treatment. Spinal Cord. 2016;54 (Suppl 1):S14-23.

5. Barrera-Chacon JM, Mendez-Suarez JL, Jauregui-Abrisqueta ML, Palazon R, Barbara-Bataller E, Garcia-Obrero I. Oxycodone improves pain control and quality of life in anticonvulsantpretreated spinal cord-injured patients with neuropathic pain. Spinal Cord. 2011;49:36-42.
6. Norrbrink C, Lundeberg T. Tramadol in neuropathic pain after spinal cord injury: a randomized, double-blind, placebo-controlled trial. Clin J Pain. 2009;25:177-84.

7. Mehta S, McIntyre A, Janzen S, Loh E, Teasell R, Spinal cord injury rehabilitation evidence team. Systematic review of pharmacologic treatments of pain after spinal cord injury: an update. Arch Phys Med Rehabil. 2016;97:1381-91.e1.

8. Dowell D, Haegerich TM, Chou R. CDC Guideline for Prescribing Opioids for Chronic Pain--United States, 2016. JAMA. 2016;315:1624-45.

9. Frank JW, Lovejoy TI, Becker WC, Morasco BJ, Koenig CJ, Hoffecker L, et al. Patient outcomes in dose reduction or discontinuation of long-term opioid therapy: a systematic review. Ann Intern Med. 2017;167:181-91.

10. Frank JW, Levy C, Matlock DD, Calcaterra SL, Mueller SR, Koester S, et al. Patients' perspectives on tapering of chronic opioid therapy: A Qualitative Study. Pain Med Malden Mass. 2016;17:1838-47.

11. Ballantyne JC, Mao J. Opioid therapy for chronic pain. N Engl J Med. 2003;349:1943-53.

12. Kaplovitch E, Gomes T, Camacho X, Dhalla IA, Mamdani MM, Juurlink DN. Sex differences in dose escalation and overdose death during chronic opioid therapy: a Population-Based Cohort Study. PLoS ONE. 2015;10:e0134550.

13. Chiodo AE, Sitrin RG, Bauman KA. Sleep disordered breathing in spinal cord injury: a systematic review. J Spinal Cord Med. 2016;39:374-82.

14. Van Ryswyk E, Antic NA. Opioids and sleep-disordered breathing. Chest. 2016;150:934-44.

15. Gomes T, Mamdani MM, Dhalla IA, Paterson JM, Juurlink DN. Opioid dose and drug-related mortality in patients with nonmalignant pain. Arch Intern Med. 2011;171:686-91.

16. Jones CM, McAninch JK. Emergency department visits and overdose deaths from combined use of opioids and benzodiazepines. Am J Prev Med. 2015;49:493-501.

17. Park TW, Saitz R, Ganoczy D, Ilgen MA, Bohnert ASB. Benzodiazepine prescribing patterns and deaths from drug overdose among US veterans receiving opioid analgesics: case-cohort study. BMJ. 2015;350:h2698.

18. Dasgupta N, Funk MJ, Proescholdbell S, Hirsch A, Ribisl KM, Marshall S. Cohort Study of the Impact of High-Dose Opioid Analgesics on Overdose Mortality. Pain Med Malden Mass. 2016;17:85-98.

19. Berlowitz DJ, Brown DJ, Campbell DA, Pierce RJ. A longitudinal evaluation of sleep and breathing in the first year after cervical spinal cord injury. Arch Phys Med Rehabil. 2005;86:1193-9.

20. American Psychiatric Association. Diagnostic and statistical manual of mental disorders. 5th edn. American Psychiatric Association, Arlington, VA. 2013.

21. Edlund MJ, Martin BC, Russo JE, DeVries A, Braden JB, Sullivan MD. The role of opioid prescription in incident opioid abuse and dependence among individuals with chronic noncancer pain: the role of opioid prescription. Clin J Pain. 2014;30:557-64.

22. Jones CM, Campopiano M, Baldwin G, McCance-Katz E. National and state treatment need and capacity for opioid agonist medication-assisted treatment. Am J Public Health. 2015;105: e55-63.

23. FDA Analysis of long term trends in prescription opioid analgesic products: quantity, sales, and price trends. 2018. https://www.fda. gov/downloads/AboutFDA/ReportsManualsForms/Reports/ UCM598899.pdf. 